\title{
Poly(vinyl chloride)-grafted multi-walled carbon nanotubes via Friedel-Crafts alkylation
}

\author{
X. L. Wu, P. Liu* \\ Key Laboratory of Nonferrous Metal Chemistry and Resources Utilization of Gansu Province and State Key Laboratory \\ of Applied Organic Chemistry, College of Chemistry and Chemical Engineering, Lanzhou University, Lanzhou 730000, \\ China
}

Received 14 June 2010; accepted in revised form 21 July 2010

\begin{abstract}
A novel approach was developed for the surface modification of the multi-walled carbon nanotubes (MWCNTs) with high percentage of grafting (PG\%) by the grafting of polymer via the Friedel-Crafts alkylation. The graft reaction conditions, such as the amount of catalyst added, the reaction temperature, and the reaction time were optimized for the Friedel-Crafts alkylation of the MWCNTs with poly(vinyl chloride) (PVC) with anhydrous aluminum chloride $\left(\mathrm{AlCl}_{3}\right)$ as catalyst in chloroform $\left(\mathrm{CHCl}_{3}\right)$. The Fourier Transform Infrared (FT-IR), Raman, and thermogravimetric (TGA) analysis showed that PVC had been successfully grafted onto MWCNTs both at the ends and on the sidewalls by the proposed Friedel-Crafts alkylation. The PVC grafted MWCNTs (PVC-MWCNTs) could be dispersed well in organic solvent and the dispersion was more stable.
\end{abstract}

Keywords: nanomaterials, carbon nanotubes, surface modification, Friedel-Crafts alkylation, polyvinyl chloride

\section{Introduction}

Carbon nanotubes (CNTs) have won more and more intense interest since their discovery because of their unique structural, mechanical and electronic properties [1-3]. However, the processing of CNTs has been limited by their insolubility in most common solvents, due to the strong inter-tube van der Waals attraction [4].

Consequently, various methods have been proposed for functionalizing CNTs. Functionalization of CNTs with polymers is gaining comprehensive interest because the polymer chains can promote the solubility of CNTs in common solvents. The widely used methods for the chemical functionalization of CNTs are the 'grafting to' and 'grafting from' approaches [5]. The functional groups, such as carboxyl groups [6] or amino groups [7] for the 'grafting to' approaches, and initiating groups [8] or polymerizable groups [9] for the 'grafting from' approaches, must be introduced onto the surfaces of CNTs before the grafting reactions.

Most recently, the research interest in the research field has focused on the 'free radical addition' [10-12] and 'anionic addition' [13, 14] approaches for the chemical functionalization of CNTs by the addition reaction of the polymer radicals or polymer anions on the surface $\pi$-bonds of the CNTs. These approaches seem to be simpler than the 'grafting to' and 'grafting from' approaches because the surface modification of the CNTs with the functional groups is not needed.

Friedel-Crafts reaction has been successfully applied for the chemical functionalization of carbon nanofibers [15] and CNTs with small molecules [16, 17]. In the present work, we report the grafting of poly(vinyl chloride) (PVC) onto multi-walled car-

*Corresponding author, e-mail: pliu@lzu.edu.cn

(C) BME-PT 
bon nanotubes (MWCNTs) MWCNTs both at the ends and on the sidewalls via the Friedel-Crafts alkylation reaction with anhydrous aluminum chloride $\left(\mathrm{AlCl}_{3}\right)$ as catalyst for the first time. Similarly to the 'free radical addition' and 'anionic addition' approaches, the pre-functionalization of the MWCNTs with functional groups is not needed. Furthermore, the pristine MWCNTs without any treatment were used in the proposed method. Therefore, the original length of the MWCNTs remained.

\section{Experimental}

\subsection{Materials}

MWCNTs, synthesized by a thermal chemical vapor deposition method, were obtained from Shenzhen Nanotech Port Co., Ltd. (Shenzhen, China) with an average diameter of 20-40 nm and a purity of $95 \%$. The MWCNTs were used without any purification process.

PVC was bought from the Chemical factory of Yanguoxia in Gansu, and dried in vacuum. Anhydrous aluminum chloride $\left(\mathrm{AlCl}_{3}\right)$ was provided by Sitong Chemical Factory in Tianjin. Chloroform $\left(\mathrm{CHCl}_{3}\right)$ was dehydrated with anhydrous calcium chloride $\left(\mathrm{CaCl}_{2}\right)$ and then distilled under reduced pressure. Other solvents were analytical grade obtained from Tianjin Chemical Co. Ltd.

\subsection{Friedel-Crafts alkylation}

For a typical Friedel-Crafts alkylation reaction, $0.20 \mathrm{~g}$ MWCNTs, certain amount of anhydrous aluminum chloride, and dehydrated chloroform $30 \mathrm{ml}$ were combined into a three neck flask. Then the mixture was stirred electromagnetically at certain temperature for certain time under nitrogen atmosphere. After being cooled to room temperature, the mixture was dispersed in THF with ultrasonic vibration and centrifuged (12 $000 \mathrm{rpm}$ for $10 \mathrm{~min}$ ) until no PVC could be detected in the supernatant liquid. The resulting products, poly(vinyl chloride) grafted MWCNTs (PVC-MWCNTs), were dried naturally. The conditions of the Friedel-Crafts alkylation reaction were summarized in Table 1.

For comparison, the reaction was also conducted without PVC or MWCNTs at $60^{\circ} \mathrm{C}$ for $30 \mathrm{~h}$.

\subsection{Analysis and characterizations}

A Bruker IFS $66 \mathrm{v} / \mathrm{s}$ infrared spectrometer was used for the Fourier transform infrared (FTIR) spectroscopy analysis. Raman measurements were carried out on the powder samples using FT-Raman spectrometer (BRUKER RFS 100/S) with the excitation laser of Nd:YAG (wavelength: $1064 \mathrm{~nm}$ ). The morphologies of the MWCNTs and PVCMWCNTs were characterized with a JEM-1200 EX/S transmission electron microscope (TEM). The powders were dispersed in THF in an ultrasonic bath for $5 \mathrm{~min}$, and then deposited on a copper grid covered with a perforated carbon film.

Thermogravimetric analysis (TGA) was performed with a Perkin-Elmer TGA-7 system at a scan rate of $20^{\circ} \mathrm{C} \cdot \mathrm{min}^{-1}$ to $800^{\circ} \mathrm{C}$ in $\mathrm{N}_{2}$. The percentage of grafting (PG\%) of the PVC-MWCNTs was calculated from the TGA analysis.

\section{Results and discussion}

Friedel-Crafts alkylation, an electrophilic substitution reaction between aromatic rings and a chloroalkane with strong Lewis acids as catalysts, allows the synthesis of alkylated products via the reaction of arenes with alkyl halides or alkenes. Recently, it had been used for the surface chemical

Table 1. The conditions of the Friedel-Crafts alkylation reaction

\begin{tabular}{|c|c|c|c|c|c|}
\hline \multirow{2}{*}{ Samples } & \multicolumn{3}{|c|}{ Reaction conditions } & \multirow{2}{*}{$\begin{array}{c}\text { Weight loss at } \\
400^{\circ} \mathrm{C}[\%]\end{array}$} & \multirow{2}{*}{ PG\% } \\
\hline & Catalyst [g] & Reaction temperature $\left[{ }^{\circ} \mathrm{C}\right]$ & Reaction time [h] & & \\
\hline MWCNTs $_{\mathrm{c}}$ & 0.50 & 60 & 30 & 4.91 & - \\
\hline $\mathrm{PVC}_{\mathrm{c}}$ & 0.50 & 60 & 30 & 67.27 & - \\
\hline PVC-MWCNTs 1 & 0.50 & 60 & 6 & 38.58 & 117.4 \\
\hline PVC-MWCNTs 2 & 0.50 & 60 & 12 & 39.32 & 123.1 \\
\hline PVC-MWCNTs 3 & 0.50 & 60 & 18 & 39.94 & 128.2 \\
\hline PVC-MWCNTs 4 & 0.50 & 60 & 24 & 43.00 & 156.9 \\
\hline PVC-MWCNTs 5 & 0.50 & 60 & 30 & 44.87 & 178.4 \\
\hline PVC-MWCNTs 6 & 0.75 & 60 & 30 & 46.64 & 202.3 \\
\hline PVC-MWCNTs 7 & 1.00 & 60 & 30 & 49.27 & 246.4 \\
\hline PVC-MWCNTs 8 & 0.50 & 50 & 30 & 33.44 & 84.3 \\
\hline
\end{tabular}


functionalization of the carbon nanotubes with small organic molecules, such as lauroyl chloride [16] and 4-(2,4,6-trimethylphenoxy)benzamide (TMPBA) [17]. Here the reaction was used for the grafting of poly(vinyl chloride) (PVC) onto the surfaces of MWCNTs with anhydrous aluminum chloride as catalyst.

The TGA curves of the poly(vinyl chloride) grafted multi-walled carbon nanotubes (PVC-MWCNTs)
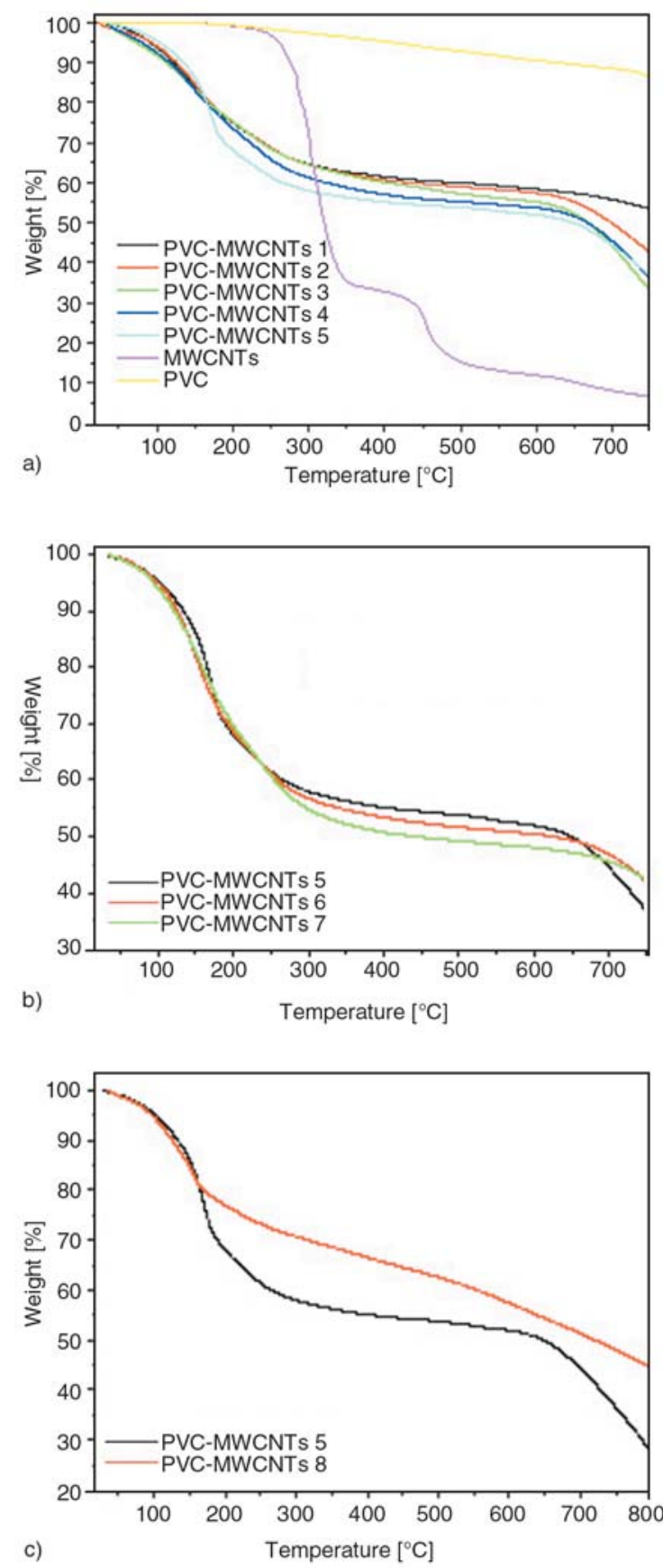

Figure 1. TGA curves of the PVC-MWCNTs obtained from the different reaction conditions: (a) effect of the reaction time; (b) effect of the catalyst added; and (c) effect of the reaction temperature prepared with different reaction conditions, the product from the comparative experiment without PVC (defined as MWCNTs $\mathrm{s}_{\mathrm{c}}$ ) or without MWCNTs (defined as $\mathrm{PVC}_{\mathrm{c}}$ ) are presented in Figure 1. The weight loss of less than $5 \%$ was found in the comparative MWCNTs sample (MWCNTs $\mathrm{M}_{\mathrm{c}}$ ) until $400^{\circ} \mathrm{C}$, it indicated that nearly no $\mathrm{CHCl}_{3}$ has reacted with the CNTs under the reaction condition. However, the comparative $\mathrm{PVC}$ sample $\left(\mathrm{PVC}_{\mathrm{c}}\right)$ had a weight loss of near to $70 \%$ in the temperature range of $200-400^{\circ} \mathrm{C}$, as summarized in Table 1 . So the percentage of grafting (PG\%) could be calculated by the comparison of the weight loss of $\mathrm{PVC}_{\mathrm{c}}$ and MWCNTs $_{c}$ with those of the PVC-MWCNTs until $400^{\circ} \mathrm{C}$ (Table 1). The lower on-set thermal decomposition temperature of the PVC-MWCNTs than that of the pure PVC might be caused by the residual catalyst $\mathrm{AlCl}_{3}$, which is also the catalyst for the thermal decomposition of PVC [18].

The effect of the reaction conditions on the percentage of grafting (PG\%) of the products, the poly(vinyl chloride) grafted multi-walled carbon nanotubes (PVC-MWCNTs), calculated from their TGA analysis (Figure 1), were summarized in Table 1. The PVC-MWCNTs samples (1-8) had the PG\% in the range of about $110-180 \%$. It means that $1.10-1.80 \mathrm{~g}$ PVC had been grafted onto per gram of the pristine MWCNTs. It is much higher than the polymer grafted CNTs with other methods. It might be due to the crosslinking reaction of PVC under the grafting condition because that the comparative $\mathrm{PVC}$ sample $\left(\mathrm{PVC}_{\mathrm{c}}\right)$ was gel and could not be dissolved in THF. Furthermore, the strategy developed is facile because that the pre-functionalization of the CNTs is not needed. So another strong point emerges that the length of the pristine CNTs could be maintained in the procedure. It could be concluded that the longer reaction time, more catalyst added, and higher reaction temperature favored the Friedel-Crafts alkylation between MWCNTs and PVC.

After the Friedel-Crafts alkylation of the pristine MWCNTs with PVC and the extraction of the products with THF, some absorbance peaks such as the symmetrical stretching vibrations of $\mathrm{C}-\mathrm{Cl}$ at $600-700 \mathrm{~cm}^{-1}$, stretching vibrations of $\mathrm{C}-\mathrm{H}$ at 2930, 2850, and $1250 \mathrm{~cm}^{-1}$, asymmetrical vibrations of $-\mathrm{CH}_{2}$ at $1420 \mathrm{~cm}^{-1}$, which do not exist in the FTIR spectrum of the pristine MWCNTs, appeared in that of the PVC-MWCNTs (Figure 2). 


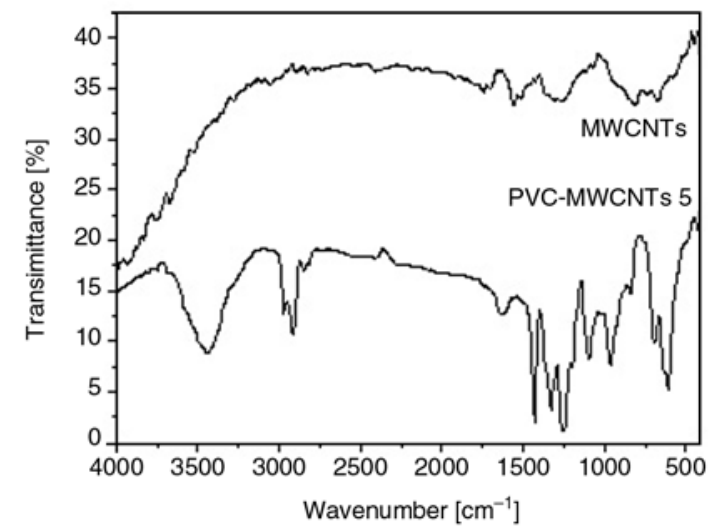

Figure 2. FT-IR spectra of the pristine MWCNTs and the PVC-MWCNTs 7

It indicated that the PVC molecules had been successfully grafted onto the surfaces of the MWCNTs via the Friedel-Crafts alkylation. The grafting mechanism could be deduced as shown in Figure 3 .

Raman spectrum has been prevalently applied for providing qualitative information on the status of the sidewall functionalization of CNTs. The Raman spectrum of the pristine MWCNTs and the PVCMWWNTs are shown in Figure 4. Two usual bands of CNTs were detected for the MWCNTs: the D-band (the vibration of $\mathrm{sp}^{2}$-bonded carbon atoms in a two-dimensional hexagonal lattice, such as in a graphitic layer) at $1290 \mathrm{~cm}^{-1}$ and the G-band (scattering from $\mathrm{sp}^{3}$-hybridized carbons defects in the hexagonal framework of the MWCNTs walls) at $1600 \mathrm{~cm}^{-1}$. The value of intensity ratio between the D- and G-bands $\left(I_{\mathrm{D}} / I_{\mathrm{G}}\right)$ is an indication of the degree of the covalent functionalization of the MWCNTs. Figure 4 showed that $I_{\mathrm{D}} / I_{\mathrm{G}}$ of the pristine MWCNTs was about 0.74 , while $I_{\mathrm{D}} / I_{\mathrm{G}}$ was around 1.68 for the PVC-MWWNTs. $I_{\mathrm{D}} / I_{\mathrm{G}}$ of the MWCNTs was enhanced, indicating that more $\mathrm{sp}^{3}$-hybridized carbons of the nanotube sidewalls were produced after the Friedel-Crafts alkylation.

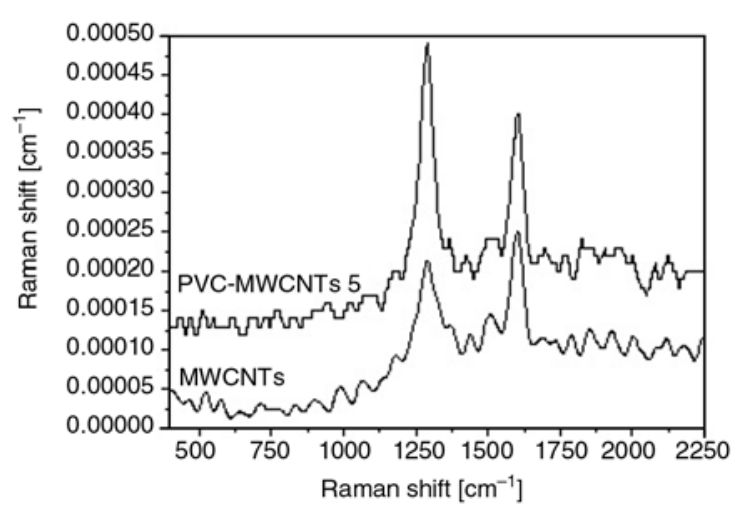

Figure 4. Raman spectra of the pristine MWCNTs and the PVC-MWCNTs 7

Transmission electron microscopy (TEM) was employed to detect the structure and morphology of the resulting samples (Figure 5). In the image of the pristine MWCNTs (Figure 5a), it is clear that many pristine MWCNTs were piled up and the average diameter of the pristine MWCNTs is in the range of 20-40 nm. The surface of the pristine MWCNTs is featureless. The convex surfaces of the pristine MWCNTs seem to be smooth with nothing adhering to them. In contrast, it can be found that after the surface Friedel-Crafts alkylation, the surfaces of the MWCNTs are coated with a PVC layer (Figure 5b). Obviously, a core-shell structure with MWCNTs at the center can be clearly observed for the nanohybrids. Furthermore, compared with the pristine MWCNTs, the external diameters of the functionalized MWCNTs was about 30-60 nm which was remarkably increased. As a consequence, we believe such ideal wrapping would be the result of covalent grafting.

Dispersion of the pristine MWCNTs into aqueous solution or organic solvent was very difficult even after it was ultrasonically irradiated. However, dispersion of the PVC-MWCNTs into polar solvents

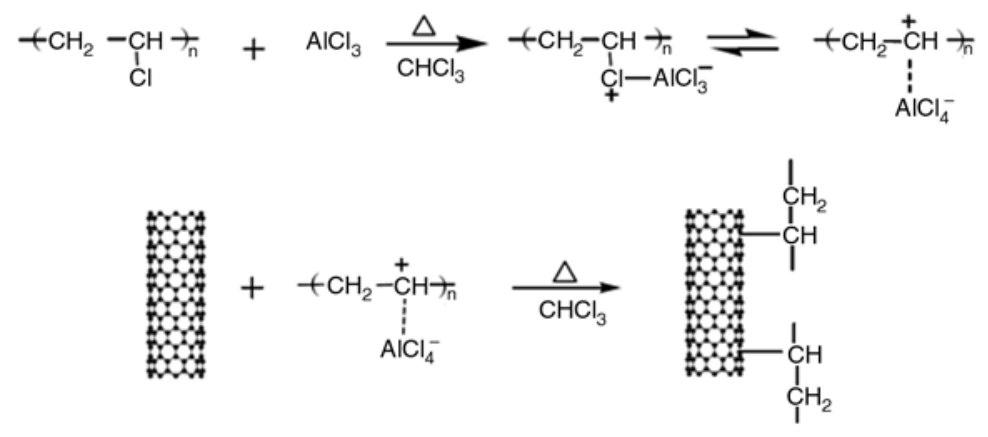

Figure 3. Proposed mechanism of grafting reaction 


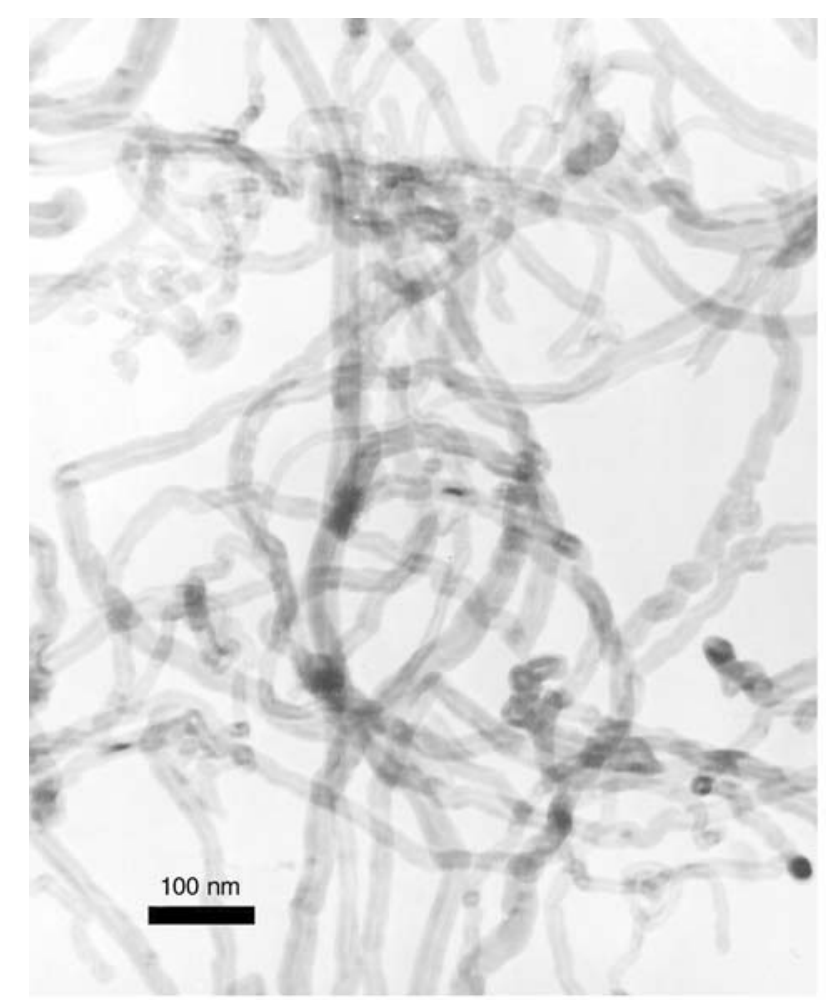

a)

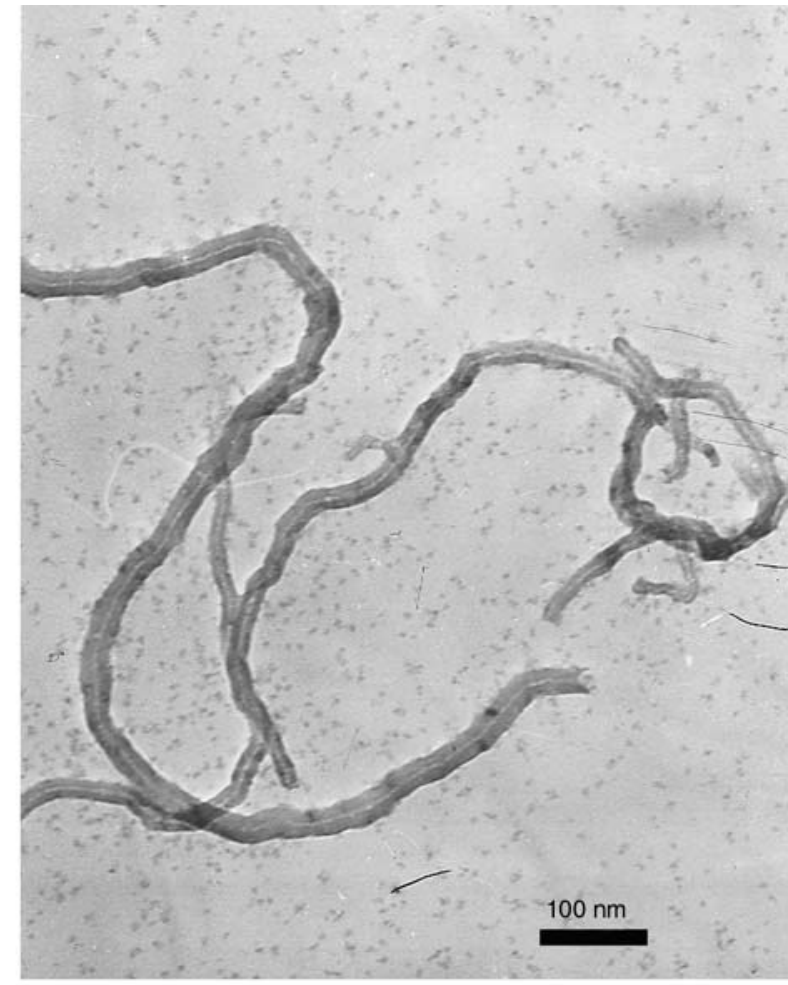

b)

Figure 5. TEM images of the pristine MWCNTs and the PVC-MWCNTs 7: (a) pristine MWCNTs; and (b) PVC-MWCNTs 7

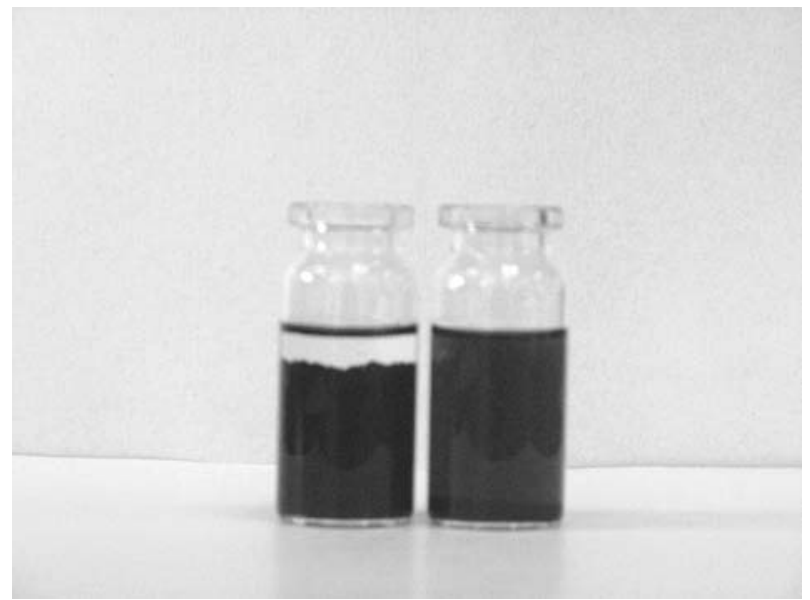

Figure 6. Photographs of the pristine MWCNTs (left) and the PVC-MWCNTs (right) dispersed in THF

such as tetrahydrofuran (THF) was very easy. So the solubility or dispersibility of the functionalized MWCNTs strongly depends on the structure and amounts of the grafted moieties. Figure 6 gives the digital photos of the pristine MWCNTs and the PVC-MWCNTs in THF. It is clear that the dispersibility of the pristine MWCNTs in THF is very poor, and they were only swollen (left). However, the PVC-MWCNTs are dispersable in THF, forming a homogeneous dispersion, and there was no sedimentation observed even after one month as shown in Figure 6 (right). All of the evidence indicates that PVC chains have grafted onto the surface of the MWCNTs via the Friedel-Crafts alkylation.

\section{Conclusions}

In summary, a facile strategy was developed for the grafting of polymers onto the the ends and sidewalls of the carbon nanotubes via the Friedel-Crafts alkylation catalyzed with strong Lewis acids. The TGA analysis proved that the precedentless high PG\% was achieved. The modified MWCNTs exhibited excellent dispersibility in THF and the dispersion had good stability. It is expected that the strategy could be extended to the surface modification of CNTs with other polymers by using the FriedelCrafts reactions.

\section{References}

[1] Sinnott S. B., Andrews R.: Carbon nanotubes: Synthesis, properties, and applications. Critical Reviews in Solid State and Materials Sciences, 26, 145-249 (2001).

DOI: $\underline{10.1080 / 20014091104189}$ 
[2] Terrones M.: Science and technology of the twentyfirst century: Synthesis, properties, and applications of carbon nanotubes. Annual Review of Materials Research, 33, 419-501 (2003).

DOI: 10.1146/annurev.matsci.33.012802.100255

[3] Tasis D., Tagmatarchis N., Bianco A., Prato M.: Chemistry of carbon nanotubes. Chemical Reviews, 106, 1105-1136 (2006). DOI: $10.1021 / \mathrm{cr} 050569 \mathrm{o}$

[4] Baughman R. H., Zakhidov A. A., de Heer W. A.: Carbon nanotubes - The route toward applications. Science, 297, 787-792 (2002). DOI: $10.1126 /$ science. 1060928

[5] Liu P.: Modifications of carbon nanotubes with polymers. European Polymer Journal, 41, 2693-2703 (2005).

DOI: $10.1016 /$ j.eurpolymj.2005.05.017

[6] Shi J-H., Yang B-X., Goh S. H.: Covalent functionalization of multiwalled carbon nanotubes with poly(styrene-co-acrylonitrile) by reactive melt blending. European Polymer Journal, 45, 1002-1008 (2009). DOI: 10.1016/j.eurpolymj.2008.12.040

[7] Zhang K., Lim J. Y., Choi H. J.: Amino functionalization and characteristics of multi-walled carbon nanotubes/poly(methyl methacrylate) nanocomposites. Diamond and Related Materials, 18, 316-318 (2009). DOI: $\underline{10.1016 / j . d i a m o n d .2008 .08 .005}$

[8] Baskaran D., Mays J. W., Bratcher M. S.: Polymergrafted multiwalled carbon nanotubes through surface-initiated polymerization. Angewandte Chemie International Edition, 43, 2138-2142 (2004). DOI: $10.1002 /$ anie.200353329

[9] Li S. Y., Chen H., Bi W. G., Zhou J. J., Wang Y. H., Li J. Z., Cheng W. X., Li M. Y., Li L., Tang T.: Synthesis and characterization of polyethylene chains grafted onto the sidewalls of single-walled carbon nanotubes via copolymerization. Journal of Polymer Science Part A: Polymer Chemistry, 45, 5459-5469 (2007).

DOI: $10.1002 /$ pola.22290

[10] Park S. J., Cho M. S., Lim S. T., Choi H. J., Jhon M. S.: Synthesis and dispersion characteristics of multiwalled carbon nanotube composites with poly(methyl methacrylate) prepared by in-situ bulk polymerization. Macromolecular Rapid Communications, 24, 1070-1073 (2003).

DOI: $\underline{10.1002 / \text { marc. } 200300089}$
[11] Oh S. B., Kim H. L., Chang J. H., Lee Y-W., Han J. H., An S. S. A., Joo S-W., Kim H. K., Choi I. S., Paik H-J.: Facile covalent attachment of well-defined poly(t-butyl acrylate) on carbon nanotubes via radical addition reaction. Journal of Nanoscience and Nanotechnology, 8, 4598-4602 (2008).

DOI: 10.1166/jnn.2008.IC15

[12] Liu P.: Facile graft polystyrene onto multi-walled carbon nanotubes via in situ thermo-induced radical polymerization. Journal of Nanoparticle Research, 11, 1011-1016 (2009).

DOI: $\underline{10.1007 / \mathrm{s} 11051-008-9563-0}$

[13] Baskaran D., Sakellariou G., Mays J. W., Bratcher M. S.: Grafting reactions of living macroanions with multi-walled carbon nanotubes. Journal of Nanoscience and Nanotechnology, 7, 1560-1567 (2007).

DOI: $10.1166 / j n n .2007 .459$

[14] Mountrichas G., Pispas S., Tagmatarchis N.: Graftingto approach for the functionalization of carbon nanotubes with polystyrene. Materials Science and Engineering: B, 152, 40-43 (2008).

DOI: $10.1016 /$ j.mseb.2008.06.006

[15] Baek J-B., Lyons C. B., Tan L-S.: Covalent modification of vapour-grown carbon nanofibers via direct Friedel-Crafts acylation in polyphosphoric acid. Journal of Materials Chemistry, 14, 2052-2056 (2004). DOI: $10.1039 / \mathrm{b} 401401 \mathrm{~d}$

[16] Balaban T. S., Balaban M. C., Malik S., Hennrich F., Fischer R., Rosner H., Kappes M. M.: Polyacylation of single-walled carbon nanotubes under friedel-crafts conditions: An efficient method for functionalizing, purifying, decorating, and linking carbon allotropes. Advanced Materials, 18, 2763-2767 (2006).

DOI: $10.1002 /$ adma.200600138

[17] Han S-W., Oh S-J., Tan L-S., Baek J-B.: Grafting of 4-(2,4,6-trimethylphenoxy)benzoyl onto single-walled carbon nanotubes in poly(phosphoric acid) via amide function. Nanoscale Research Letters, 4, 766-772 (2009).

DOI: $10.1007 / \mathrm{s} 11671-009-9308-8$

[18] Müller J., Dongmann G., Frischkorn C. G. B.: The effect of aluminium on the formation of PAH, methyl$\mathrm{PAH}$ and chlorinated aromatic compounds during thermal decomposition of PVC. Journal of Analytical and Applied Pyrolysis, 43, 157-168 (1997). DOI: 10.1016/S0165-2370(97)00065-X 